\title{
The Relationship Between Restoration and Furcation Involvement on Molar Teeth
}

\author{
Hom-Lay Wang, * Frederick G. Burgett, * and Yu Shyr ${ }^{\dagger}$
}

THE PURPOSE OF THIS CROSS-SECTIONAL STUDY was to examine the correlation between the presence of a crown $(\mathrm{CR})$ or a proximal restoration $(\mathrm{RE})$ and furcation involvement (FI) on molar teeth. Data were collected from 134 periodontal maintenance patients who had restored and non-restored molars present both with and without FI. A majority of the restorations that were present in these patients had been in place for at least 5 years prior to the study. First and second molars were examined clinically using the following criteria: CR, RE, FI, mobility (MO), and probing periodontal attachment level (AL). Data were analyzed with a statistical program utilizing Pearson chi-square and the pairdifference $t$ test. The results indicated that molars with CR or RE had a significantly $(P$ $<0.01$ ) higher percentage of FI but no greater mobility when compared to molars without restorations. Mean probing periodontal attachment loss was greater for restored than nonrestored molars but only with marginal significance $(P=0.051)$. There was a greater difference in mean AL between restored versus non-restored maxillary molars than for mandibular molars. This cross-sectional study provides evidence that molars with crowns or restorations involving the proximal tooth surfaces had a higher prevalence of $\mathrm{FI}$ and greater AL than molars without restorations. J Periodontol 1993;64:302-305.

Key Words: Crowns/adverse effects; dental restorations/adverse effects; furcation; periodontal attachment.

Clinical experience and reports in the literature have shown that, when compared to other teeth, molars are more vulnerable to periodontal attachment loss (AL) and are more prone to extraction. ${ }^{1-2}$ Prognosis is particularly affected when periodontal disease involves the bifurcation or trifurcation area of multi-rooted teeth. With their greater susceptibility to periodontal breakdown and their high risk to furcation involvement (FI), molars provide excellent opportunities to study etiology. Such studies are important because a more complete understanding of etiologic factors could help in the prevention of FI and improve outcomes in their treatment. Surprisingly, little research has been done to examine relationship between the presence of a crown (CR) or a proximal restoration (RE) and FI. Therefore, the aim of this research was to determine the impact of CR or RE on FI in molar teeth. A secondary but parallel aim was to evaluate the influence of tooth mobility (MO) and endodontic treatment (EN) on FI.

\section{MATERIALS AND METHODS}

One hundred thirty-four periodontal maintenance patients (62 males and 72 females) who had molars both with FI

\footnotetext{
*Department of Periodontics/Prevention and Geriatrics, School of Dentistry, University' of Michigan, Ann Arbor, MI.

${ }^{\dagger}$ Department of Biostatistics, School of Public Health.
}

and without FI and with and without restorations were selected from University of Michigan, School of Dentistry, Graduate Periodontic Clinic patient pool. The mean age of the population was 54 years. Record reviews confirmed that a majority of the selected patients had restorations present for at least 5 years prior to the study. Most of the restoration margins were supragingival in position. The clinical examinations conducted on the molars included assessment for $\mathrm{CR}$, absence or presence of a crown type restoration; $\mathrm{RE}$, absence or presence of a restoration involving the proximal surface; EN, absence or presence of endodontic treatment; FI, absence or presence of furcation involvement with exposure of $1 / 3$ or more of the width of the furca using Cowhorn explorer; MO, no mobility or mobility present of greater than $0.5 \mathrm{~mm}$ movement in the bucco-lingual direction; $\mathrm{AL}$, the distance in $\mathrm{mm}$ between the cemento-enamel junction and the apical end of the periodontal probing depth recorded for six sites on each tooth, including the mesiobuccal, mesiolingual, distobuccal, distolingual, midfacial, and midlingual. For each parameter studied, the frequency ratios for furcated and non-furcated molars with CR, RE and without restoration were calculated using a statistical program $^{\ddagger}$ and the differences were statistically analyzed by

‡SAS 6.03, SAS Institute, Cary, NC. 
Table 1. Frequency Table on Complete Data Set $(\mathbf{n}=771)$

\begin{tabular}{lcc}
\hline Variable & Absence (\%) & Presence (\%) \\
\hline Crown placement & $575(74.6)$ & $196(25.4)$ \\
Class II restoration & $595(77.1)$ & $176(22.9)$ \\
Mobility & $658(85.3)$ & $113(14.7)$ \\
Furcation involvement & $398(51.6)$ & $373(48.4)$ \\
Endodontic treatment & $734(95.2)$ & $37(4.8)$ \\
\hline
\end{tabular}

using Pearson Chi-square test. The mean AL difference and standard deviation for each different parameter were also calculated. These data were analyzed using the pair-difference $t$ test for statistical significant relationships among the different parameters within each patient.

\section{RESULTS}

The overall findings in this study population for the CR, RE, EN, FI, and MO are presented in Table 1. The 134 patients examined had 771 molars present of which 373 had FI and 362 had restorations. Mobility was present on 113 and only 37 had endodontic treatment. Chi-square analysis (Table 2) showed molars with CR or RE had a significantly $(P<0.01)$ higher presence of FI than molars without restorations. Data analysis indicated that the relationship between the restoration status of the molars and MO was not significant, while that of $\mathrm{EN}$ was significant but with a very small sample size. A significant difference in frequency of FI was found between molars with and without restorations for both the maxillary and mandibular arches (Table 3). For the mean AL difference analysis shown in Table 4, only patients with both variables were included so the number of patients in each group varies. The pair-difference $t$ test indicated that there was significantly more probing periodontal attachment loss $(P<0.05)$ in molars with RE, FI, and MO than in molars without these occurrences. When molars with $\mathrm{CR}$ and $\mathrm{RE}$ were combined and compared to unrestored molars for $\mathrm{AL}$, a marginally significant $(P=$ 0.051 ) difference in probing periodontal attachment levels was found favoring the molars without restorations. The difference in AL between molars with and without CR or RE occurred primarily on the maxillary molars (Table 5). Within the maxillary and mandibular arches individually both FI and MO were significant factors for AL (Table 6).

\section{DISCUSSION}

The results of this study indicate that molars with CR or RE have a higher prevalence of FI and greater AL than non-restored molars. It must be understood that causality cannot be shown by cross-sectional studies such as this one. To establish causality, longitudinal epidemiologic studies are required. However, these results suggest that within patients molars subjected to $\mathrm{CR}$ or RE are more likely to have furcation involvement and more probing periodontal attachment loss even though the patients are under regular maintenance care. This is in agreement with Chen et al. ${ }^{3}$ who reported that periodontal attachment loss is greater adjacent to restored tooth surfaces than adjacent to unrestored tooth surfaces. Similar findings were reported by Keszthelyl and $\mathrm{Szabo}^{4}$ who found proximal surfaces restored by amalgam had significantly more loss of attachment than unrestored surfaces. It has also been demonstrated that molars with full coverage have more soft deposits, more severe gingivitis, and deeper periodontal pockets, ${ }^{5}$ which could contribute to the increased susceptibility of molars with crowns to FI and AL. Kalkwarf et al. ${ }^{6}$ reported that periodontal lesions associated with furcations respond differently to periodontal treatment than similar lesions adjacent to other tooth surfaces. Furthermore, they indicated that during the second year of maintenance care, furcation sites exhibit more AL regardless of the type of therapy rendered. ${ }^{6}$ All these reports confirmed that teeth with FI were more vulnerable to $\mathrm{AL}$ and that they were also more likely to be extracted..$^{1-2}$ Since restored molars were shown to be more likely to be involved in the furcation, unless the FI and AL occurred prior to placement of the restoration, some factor or factors involved with the restoration must contribute to periodontal breakdown. These factors could be the restorative process itself, the location of the restoration margin, the contact relationship, trauma from occlusion, plaque retentive factors, and personal oral hygiene.

These results strongly suggest both maxillary and mandibular molars with CR and RE are more likely to have FI than molars without restoration. However, the difference in AL was found mostly on the maxillary molars (Table 5). Keszthelyl and Szabo indicated that in Class II amalgam restoration, maxillary molars exhibited a significantly greater loss of connective tissue attachment than mandibular mo-

Table 2. The Relationship Between Restorations and FI, MO, or EN (\%)

\begin{tabular}{|c|c|c|c|c|c|c|}
\hline \multirow[b]{2}{*}{ Groups } & \multicolumn{2}{|c|}{ Furcation Involvement } & \multicolumn{2}{|c|}{ Mobility } & \multicolumn{2}{|c|}{ Endodontic Involvement } \\
\hline & Absence & Presence & Absence & Presence & Absence & Presence \\
\hline $\begin{array}{l}\text { No crown placement } \\
\text { or Class II restoration } \\
(\mathrm{n}=399)\end{array}$ & 60.90 & 39.10 & 87.22 & 12.78 & 99.50 & 0.50 \\
\hline $\begin{array}{l}\text { Class II restoration } \\
(\mathrm{n}=176)\end{array}$ & 47.16 & 52.84 & 82.95 & 17.05 & 96.02 & 3.98 \\
\hline $\begin{array}{l}\text { Crown placement } \\
(\mathrm{n}=196)\end{array}$ & 36.73 & 63.27 & 83.67 & 16.33 & 85.71 & * 14.29 \\
\hline Chi-square $P$ value & \multicolumn{2}{|c|}{$0.001^{*}$} & \multicolumn{2}{|c|}{0.307} & \multicolumn{2}{|c|}{$0.001^{*}$} \\
\hline
\end{tabular}

*Statistically significant at $P<0.001$ level. 
Table 3. Frequency Distribution For Teeth With and Without Crown Placement or Class II Restoration (\%)

\begin{tabular}{|c|c|c|c|c|}
\hline \multirow[b]{2}{*}{ Group } & \multicolumn{2}{|c|}{$\begin{array}{l}\text { Furcation } \\
\text { Involvement }\end{array}$} & \multicolumn{2}{|c|}{ Mobility } \\
\hline & Absence & Presence & Absence & Presence \\
\hline \multicolumn{5}{|l|}{ Maxiliary arch (n) } \\
\hline $\begin{array}{l}\text { No crown placement or } \\
\text { Class II } \\
\text { restoration }(215)\end{array}$ & 57.67 & 42.33 & 88.37 & 11.63 \\
\hline Class II restoration (95) & 46.32 & 53.68 & 82.11 & 17.89 \\
\hline Crown placement (91) & 37.36 & 62.64 & 82.42 & 17.58 \\
\hline Chi-square $P$ value & \multicolumn{2}{|c|}{$0.003^{*}$} & \multicolumn{2}{|c|}{0.221} \\
\hline \multicolumn{5}{|l|}{ Mandibular arch (n) } \\
\hline $\begin{array}{l}\text { No crown placement or } \\
\text { Class II } \\
\text { restoration (184) }\end{array}$ & 64.67 & 35.33 & 85.87 & 14.13 \\
\hline Class II restoration (81) & 48.15 & 51.85 & 83.95 & 16.05 \\
\hline Crown placement (105) & 36.19 & 63.81 & 84.76 & 15.24 \\
\hline Chi-square $P$ value & \multicolumn{2}{|c|}{$0.001^{*}$} & \multicolumn{2}{|c|}{0.914} \\
\hline
\end{tabular}

*Statistically significant at $P<0.01$ level

Table 4. Patient Mean Attachment Loss (mm) Difference Among Groups

\begin{tabular}{lcc}
\hline & $\begin{array}{c}\mathrm{X} \pm \mathrm{SD}^{*} \\
\text { Variable (n) }\end{array}$ & \\
\hline Crown placement (56) & $-0.110 \pm 0.134$ & 0.413 \\
Class II restoration (73) & $0.231 \pm 0.113$ & 0.004 \\
Crown placement or & & \\
$\quad$ Class II restoration (83) & $0.186 \pm 0.090$ & 0.051 \\
Endodontic treatment (31) & $0.062 \pm 0.204$ & 0.763 \\
Furcation involvement (82) & $0.632 \pm 0.999$ & 0.0001 \\
MO (44) & $0.678 \pm 0.185$ & 0.0007
\end{tabular}

Both outcomes had to be present in the same individual to be included in the analysis.

${ }^{*} \mathrm{X} \pm \mathrm{SD}$ : mean difference \pm standard deviation.

Table 5. Patient Mean Attachment Loss (mm) Difference For Teeth With and Without CR or RE

\begin{tabular}{lcc}
\hline Arch $(\mathrm{n})$ & $\mathrm{X} \pm \mathrm{SD}^{*}$ & $P$ Value \\
\hline Maxillary (48) & $0.291 \pm 0.149$ & $0.056 \dagger$ \\
Mandible (36) & $0.253 \pm 0.180$ & 0.169 \\
\hline
\end{tabular}

${ }^{*} \mathrm{X} \pm$ S.D.: mean difference \pm standard deviation.

†Marginally significant at $P=0.056$ level

lars. ${ }^{4}$ Others have reported similar differences between the maxillary and mandibular arches. ${ }^{2,7}$ Pihlstrom et al. reported that maxillary teeth especially second molars were at greater risk for AL than other teeth. ${ }^{2}$ Ross and Thompson indicated that FI was more prevalent in maxillary than in mandibular molars ${ }^{7}$ which this study confirmed. Others have also reported similar results based on retrospective data. ${ }^{8,9}$

Mobility was found to be a significant factor for $\mathrm{AL}$ which is in agreement with our previous study. ${ }^{10}$ However, no connection between $\mathrm{MO}$ and FI was found. It may be that molars with both MO and FI were more likely to be extracted and be lost to the study. Since standard practice dictates protected cusp type restoration for endodontically treated molars, the finding that EN was a significant factor
Table 6. Mean Attachment Level (mm) Difference

\begin{tabular}{lrl}
\hline Variability & $\begin{array}{c}\mathrm{X} \pm \mathrm{SD}^{*} \\
\text { (Presence-Absence) }\end{array}$ & $P$ Value \\
\hline Maxillary arch (n) & & \\
$\quad$ Crown placement (31) & $0.210 \pm 0.177$ & 0.239 \\
Class II restoration (63) & $-0.190 \pm 0.125$ & 0.131 \\
Furcation involvement (44) & $0.658 \pm 0.133$ & 0.0001 \\
Mobility (26) & $0.484 \pm 0.221$ & 0.038 \\
Endodontic treatment (17) & $0.520 \pm 0.290$ & 0.091 \\
Mandibular arch (n) & & \\
Crown placement (36) & $0.249 \pm 0.153$ & 0.1127 \\
Class II restoration (51) & $-0.026 \pm 0.131$ & 0.839 \\
Furcation involvement (53) & $0.515 \pm 0.140$ & 0.0005 \\
Mobility (21) & $0.892 \pm 0.210$ & 0.0004 \\
Endodontic treatment (15) & $0.144 \pm 0.227$ & 0.5343 \\
\hline
\end{tabular}

${ }^{*} \mathrm{X} \pm$ S.D.: mean difference \pm standard deviation.

for $\mathrm{RE}$ or $\mathrm{CR}$ would be expected. EN was not a significant factor for AL.

The clinical data obtained in this study suggest that periodontitis in the furcation is associated with several factors including restorations. Controlled longitudinal studies examining such factors as occlusion, inflammation, location of gingival margin of restorations, and contact relationships could determine how restorations contribute to periodontal breakdown in furcation sites.

A major goal in our research efforts is the development of a predictable treatment for the regeneration of furcationtype periodontal defects. A number of studies have reported use of barrier membranes with or without bone grafting to treat the furcal defect; ${ }^{11-13}$ while results appear promising, these procedures remain unpredictable in outcome. Results from this study suggest that an additional factor to consider before treatment of the furcation-involved tooth is its restorative status; i.e., molar teeth had a higher prevalence of furcation involvement and were subject to greater attachment loss. Whether the presence of restorations also influences the regenerative response following surgical treatment of the furcation region is yet to be determined.

From this limited cross-sectional study, the following conclusions can be drawn: 1) molars with CR or RE had a higher prevalence of FI and greater $\mathrm{AL}$ than non-restored molars; 2) the difference in AL between restored and nonrestored molars occurred mostly in the maxillary arch;3) mobility was found to be a significant factor for AL but not FI.

\section{Acknowledgment}

The authors thank Drs. Chi-Tsai Yeh and Kuo Yuan for their help in collecting data and Ms. Robin Gembacz for her assistance in the preparation of this manuscript.

\section{REFERENCES}

1. Ramfjord SP, Knowles JW, Morrison EC, et al. Results of periodontal therapy related to tooth type. J Periodontol 1980;51:270-273.

2. Pihlstrom BL, Oliphant TH, McHugh RB. Molar and nonmolar teeth compared over $61 / 2$ years following two methods of periodontal therapy. J Periodontol 1984;55:499-504. 
3. Chen JT, Burch JG, Beck FM, Horton JE. Periodontal attachment loss associated with proximal tooth restorations. J Prosth Dent 1987;57;416-420.

4. Keszthelyl G, Szabo I. Influence of Class II amalgam fillings on attachment loss J Clin Periodontol 1984;11:81-86.

5. Silness J. Periodontal conditions in patients treated with dental bridges. J Periodont Res 1970;5:219-224.

6. Kalkwarf KL, Kaldahl WB, Patil KD. Evaluation of furcation region response to periodontal therapy. J Periodontol 1988;59:794-804.

7. Ross IF, Thompson RH. Furcation involvement in maxillary and mandibular molars. J Periodontol 1980;51:450-454.

8. Hirschfeld L, Wasserman B. A long-term survey of tooth loss in 600 treated periodontal patients. $J$ Periodontol 1978;49:225-237.

9. McFall WT. Tooth loss in 100 treated patients with periodontal disease. A long term study. J Periodontol 1982;53:539-549.

10. Wang HL, Zahn M, Burgett F, Greenwell $H$. The effect of furcation involvement on attachment loss. J Dent Res 1991;70 (Spec. Issue):282 (Abstr.).

11. Caffesse RG, Smith BA, Duff B, et al. Class Ir furcations treated by guided tissue regeneration in humans. $J$ Periodontol 1990;61:510-514.

12. Anderegg CF, Martin SJ, Gray JL, Mellonig JT, Gher ME. Clinical evaluation of the use of decalcified freeze-dried bone allograft with guided tissue regeneration in the treatment of molar furcation invasions. J Periodontol 1991;62:264-268.

13. Schallhorn R, McClain P. Combined osseous composite grafting, root conditioning, and guided tissue regeneration. Int $J$ Periodontics $R e$ storative Dent 1988;4:9-32.

Send reprint requests to: Dr. Hom-Lay Wang, University of Michigan, School of Dentistry, 1011 N. University Ave., Ann Arbor, MI 481091078 .

Accepted for publication October 25, 1992. 